\title{
Neuroplasticity, Neurotransmission and Brain-Related Genes in Major Depression and Bipolar Disorder: Focus on Treatment Outcomes in an Asiatic Sample
}

\author{
Marco Calabrò · Laura Mandelli • Concetta Crisafulli • \\ Soo-Jung Lee · Tae-Youn Jun · Sheng-Min Wang · Ashwin A. Patkar • \\ Prakash S. Masand · Francesco Benedetti · Changsu Han • \\ Chi-Un Pae $\cdot$ Alessandro Serretti
}

Received: May 23, 2018 / Published online: September 3, 2018

(C) The Author(s) 2018

\section{ABSTRACT}

Introduction: Mood disorders are common and disabling disorders. Despite the availability of over 100 psychotropic compounds, only onethird of patients benefit from first-line treatments. Over the past 20 years, many studies have focused on the biological factors

Enhanced digital content To view enhanced digital content for this article go to https://doi.org/10.6084/ m9.figshare.6894209.

Electronic supplementary material The online version of this article (https://doi.org/10.1007/s12325018-0781-2) contains supplementary material, which is available to authorized users.

M. Calabrò · C. Crisafulli

Department of Biomedical and Dental Sciences and Morphofunctional Imaging, University of Messina, Messina, Italy

L. Mandelli · A. Serretti

Department of Biomedical and Neuromotor

Sciences, Psychiatric Section, University of Bologna, Bologna, Italy

S.-J. Lee · T.-Y. Jun · S.-M. Wang · C.-U. Pae ( $\square)$ Department of Psychiatry, The Catholic University of Korea College of Medicine, Seoul, Republic of Korea

e-mail: pae@catholic.ac.kr

A. A. Patkar · C.-U. Pae

Department of Psychiatry and Behavioural Sciences, Duke University Medical Center, Durham, NC, USA modulating disease risk and response to treatments, but with still inconclusive data. In order to improve our current knowledge, in this study, we investigated the role of a set of genes involved in different pathways (neurotransmission, neuroplasticity, circadian rhythms, transcription factors, signal transduction and cellular metabolism) in the treatment outcome of major depressive disorder (MDD) and bipolar disorder (BD) after naturalistic pharmacological treatment.

Methods: Totals of 242 MDD, 132 BD patients and 326 healthy controls of Asian ethnicity (Koreans) were genotyped for polymorphisms within 19 genes. Response and remission after 6-8 weeks of treatment with antidepressants

\author{
P. S. Masand \\ Global Medical Education, New York, NY, USA \\ F. Benedetti \\ Psychiatry and Clinical Psychobiology Unit, \\ Division of Neuroscience, San Raffaele Scientific \\ Institute, Milan, Italy \\ C. Han \\ Department of Psychiatry, College of Medicine, \\ Korea University, Seoul, Republic of Korea \\ C.-U. Pae \\ Cell Death Disease Research Center, College of \\ Medicine, The Catholic University of Korea, Seoul, \\ Republic of Korea
}


and mood stabilizers were evaluated. In secondary analyses, genetic associations with disease risk and some disease-associated features (age of onset, suicide attempt and psychotic BD) were also tested.

Results: None of the variants within the investigated genes was significantly associated with treatment outcomes. Some marginal association (uncorrected $p<0.01$ ) was observed for HTR2A, BDNF, CHL1, RORA and HOMER1 SNPs. In secondary analyses, HTR2A (rs643627, $p=0.002$ ) and CHL1 (rs4003413, $p=0.002$ ) were found associated with risk for $\mathrm{BD}$, HOMER1 (rs6872497, $p=0.002$ ) with lifetime history of suicide attempt in patients, and RORA with early onset and presence of psychotic features in BD. Marginal results were also observed for ST8SIA2 and COMT.

Discussion: Despite limitations linked to multiple testing on small samples, methodological shortcomings and small significance of the findings, this study may support the involvement of some candidate genes in the outcomes of treatments for mood disorders, as well as in $\mathrm{BD}$ risk and other disease features.

Keywords: $B D N F$; CHL1; Bipolar disorder; HOMER1; HTR2A; Major depression; Neuroplasticity; Neurotransmission; RORA; Signal transduction

\begin{tabular}{|c|c|}
\hline \multicolumn{2}{|c|}{ Abbreviations } \\
\hline 5HTR2A & Serotonin receptor $2 \mathrm{~A}$ \\
\hline CHL1 & $\begin{array}{l}\text { Cell adhesion molecule with } \\
\text { homology to L1CAM }\end{array}$ \\
\hline CREB1 & $\begin{array}{l}\text { C-AMP response element-binding } \\
\text { protein } 1\end{array}$ \\
\hline ESYT2 & $\begin{array}{l}\text { Extended synaptotagmin-like protein } \\
2\end{array}$ \\
\hline GSK3B & Glycogen synthase kinase $3 \mathrm{~B}$ \\
\hline HOMER1 & Homer scaffolding protein 1 \\
\hline NCAPG2 & $\begin{array}{l}\text { Non-SMC condesin II complex } \\
\text { subunit G2 }\end{array}$ \\
\hline PLA2G4A & Phospholipase A2 group IVA \\
\hline PPP3CC & $\begin{array}{l}\text { Protein phosphatase 3-catalytic } \\
\text { subunit-gamma isozyme }\end{array}$ \\
\hline S100B & S100 calcium binding protein B \\
\hline SIGMAR1 & $\begin{array}{l}\text { Sigma non-opioid intracellular } \\
\text { receptor } 1\end{array}$ \\
\hline SP4 & Transcription factor Sp4 \\
\hline
\end{tabular}

TXNRD2 Thioredoxin reductase 2

VIPR2 Vasoactive intestinal peptide receptor 2

WDR60 WD repeat domain 60

\section{INTRODUCTION}

Mood disorders, either unipolar (MDD) or bipolar (BD), are common and disabling conditions, with relevant consequences at the individual and social level [1]. To date, several drugs are available for the treatment of depressive and manic phases, but their effectiveness is limited and subject to wide interindividual variability. Only one-third of patients gain benefit from first antidepressant treatment in clinical settings [2], and half of the patients with BD relapse within 2 years of treatment [3]. This is also because the etiopathogenic factors leading to the risk to develop mood disorders are not yet understood.

Several studies have investigated the possible involvement of heritable factors, and therefore the variations at the level of single or multiple genes, both in disease risk and the interindividual variability in response to pharmacological treatments [4-9]. However, to date, no definite results have been obtained, since individual genes explain only small and partial effects of complex phenotypes [10]. There is indeed much evidence in the literature of stronger and/or more selective genetic associations with disease-associated features or component phenotypes (e.g., a deep phenotyping approach [11]) than with a main complex phenotype (e.g., diagnosis). Studies aimed at component phenotypes and their biological basis could therefore be promising for a better understanding of genetic effects [11].

However, the several studies conducted so far have identified certain genes as possibly associated with mood disorders, response to psychotropic drugs and disease-associated features. These candidate genes are mainly involved in (but not limited to) monoaminergic neurotransmission, neuroplasticity and circadian rhythm pathways [12-14]. Mechanisms of signal transduction, transcription factors and pathways related to cellular metabolism have 
also been associated with mood disorder risk and response variability to pharmacological treatments [15-19].

Several genes are involved in neuroplasticity and neurotransmission pathways. Among these, brain-derived neurotrophic factor $(B D N F)$ is a recognized regulator of synaptic function, with structural and functional effects [20]. Cell adhesion molecule L1-like (CHL1) product guides migrating cells and growing neurites during development and learning in adulthood [21]. Sialyltranferase X (ST8SIA2) is involved in the regulation of the adhesive properties of the neuronal cell adhesion molecule [22]. Among genes related to neurotransmission, Serotonin receptor 2A (HTR2A) and Catechol-O-methyltransferase (COMT) are known key factors involved in neurotransmission, psychiatric disorders and the mechanism of action of several psychotropic drugs [23, 24]. Homer 1 protein (HOMER 1) belongs to a family of scaffolding proteins interacting with various post-synaptic density (PSD) proteins, where multiple neurotransmitter converge [25]. Related Orphan Receptor A (RORA) plays a role in several physiological processes including circadian rhythm, with consistent evidence of involvement in mood disorders [26].

In a previous study [27], we investigated a set of 14 candidate genes involved in neuroplasticity, monoamine, circadian rhythm and transcription factor pathways as potentially related to individual responses to antidepressant treatment in MDD patients of Caucasian ancestry. We found that some genes involved in synaptic plasticity, neural activity and connectivity (CREB1, ZNF804A and CHL1), might be associated with an antidepressant response. In the present study, we investigated a set of 19 genes involved in the same pathways (neuroplasticity, monoamine, circadian rhythm, and transcription factor pathways) in a sample of Asian ethnicity (Korean), including both MDD and BD patients. Twelve of the genes investigated here were the same as tested on the European sample [27] (see genetic analysis for details).

In the present study, we hypothesized that the genes we previously found associated with responses to antidepressant treatment in our
Caucasian sample might also influence the response to treatments for mood disorders in Asian subjects, treated with both antidepressants and antimanic agents. The genes were originally selected based on their involvement either in the risk of disease, the response to treatment or other associated characteristics, as reported in previous literature. Therefore, in secondary analyses, we also hypothesized a possible involvement of these genes in the risk of developing the disease and as affecting some of the disease variables that we systematically collected (age of onset, lifetime history of suicide attempts, psychotic BD).

\section{METHODS}

\section{Subjects}

The samples considered for primary analysis in this study were comprised of 242 patients diagnosed with MDD and 132 patients diagnosed with BD according to the Diagnostic and Statistical Manual of Mental Disorders IV criteria [28] consecutively admitted to the Department of Psychiatry of Seoul St. Mary's Hospital for pharmacological treatment. A total of 326 controls were also collected at the same site. Controls were consecutively collected among hospital staff and non-psychiatric hospital patients, who did not satisfy criteria for current or past psychiatric disorder. Non-psychiatric subjects suffering from moderate-severe, unstable medical or neurological conditions potentially affecting their psychological status and psychiatric evaluations were systematically excluded from the control sample. Recruitment details and exclusion criteria for patients have been previously described $[29,30]$. Briefly, all patients had to be eligible for pharmacological treatment. MDD patients had to satisfy criteria for a current episode of MDD requiring treatment with antidepressants, while BD patients had to satisfy criteria for a current manic/mixed episode requiring treatment with mood stabilizers (for assessing antimanic effects with mood stabilizers (e.g., [29, 31-34]). Patients were all undergoing naturalistic treatments with venlafaxine or paroxetine (MDD), lithium, 
valproate, carbamazepine and lamotrigine (BD). The choice of treatment was taken by the clinician based on international guidelines. Due to intent prior to the present study, only MDD patients treated with venlafaxine and paroxetine were included in this sample. A severe or unstable medical and/or neurological conditions, treatment with a long-acting antipsychotic, current or recent (past 6 months) comorbidity for alcohol/substance use disorder represented exclusion criteria. All the subjects were Koreans, of Korean ancestry.

The local ethical committee approved the study procedures, and all the subjects were included after they had signed an informed consent. Socio-demographic and clinical

Table 1 Socio-demographic and clinical data

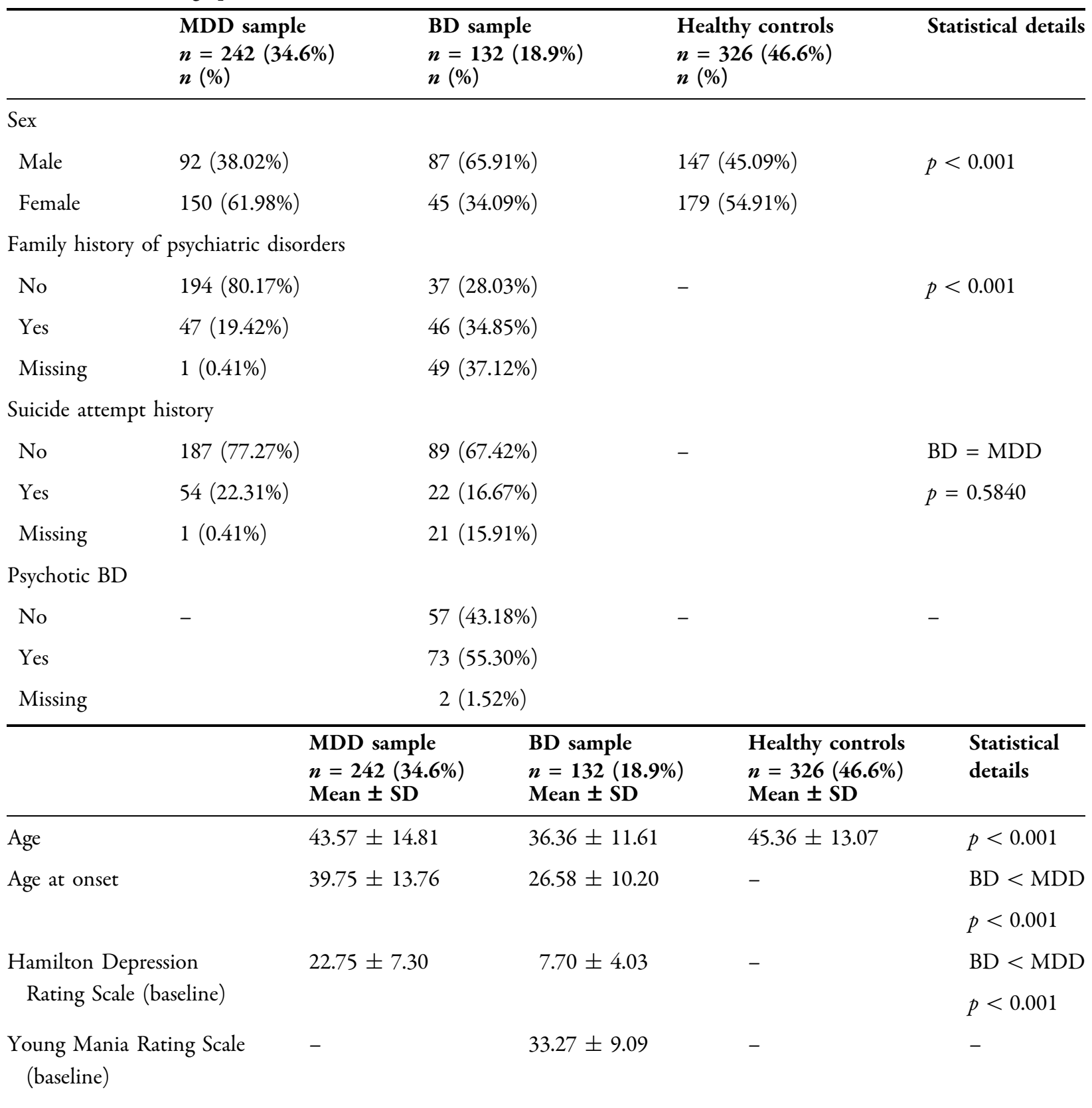


features of the samples are reported in Table 1. Case and controls were not different in terms of sex distribution $(p=0.39)$ and only marginally in terms of age $(p=0.08)$.

\section{Assessment}

Patients and controls were evaluated for psychiatric disorders by the Mini-International Neuropsychiatric Interview [28]. Demographic and clinical variables, including family history for psychiatric disease, age at first illness episode (onset) and history of suicide attempt, were systematically collected by clinical interviews and review of clinical charts. In BD patients, the presence of psychotic features was also systematically collected. Depressive symptoms severity was evaluated by the Hamilton Depression Rating Scale (HDRS) [35] in both MDD and BD patients. Manic symptoms (BD patients only) were evaluated by the Young Mania Rating scale (YMRS) [36].

Response to antidepressant treatment, remission and resistance to treatments (primary outcomes) were defined according to Schosser et al. [37]. Briefly, response to treatment is defined as a $\geq 50 \%$ improvement of HDRS scores from baseline to endpoint; remission as a HDRS score of $\leq 7$ at the endpoint; and resistance as non-response to at least two adequate consecutive antidepressant trials (including the present one) [37]. The efficacy of mood stabilizers was evaluated in terms of response, defined as a $\geq 50 \%$ improvement of YMRS scores from baseline to endpoint, and remission defined as YMRS total score $\leq 12$ [36].

\section{Genetic Analyses}

Genetic single nucleotide polymorphisms (SNPs) were chosen as previously described [27], but in the context of the Asian population. Briefly, SNPs were selected based on (1) a reported prevalence of at least $5 \%$ for the variant allele among the Asian population according to http://hapmap.ncbi.nlm.nih.gov; (2) tagging approach [complete linkage disequilibrium $(\mathrm{R} 2 \geq 0.08)$ with one or more neighbor SNPs]; (and 3) availability of a validated assay.
High-throughput genotyping using a pyrosequencer (Biotage, Sweden) was used to genotype the genomic desossiribonucleic acid (DNA) from blood. Polymerase chain reaction primers (Bioneer, Daejeon, Korea) and sequencing primers (Bioneer) used for the pyrosequencing assay were designed through Pyrosequencing Assay Design Software v.1 (Biotage), and 1 primer of each primer set was biotinylated. A total of 141 SNPs within 19 genes were initially genotyped for this study. After pruning according to genotyping rate and minor allele frequency (MAF) within the sample under investigation, 132 SNPs remained. Three SNPs were excluded since they were not in Hardy-Weinberg equilibrium (HWE) (PLA2G4A rs10737276, NCAPG2-ESYT2 rs12668837 and RORA rs1403737), leaving 129 SNPs (details in Table 2).

Of the 19 genes analyzed, 12 (PLA2G4A, CREB1, CHL1, GSK3B, SP4, VIPR2, PPP3CC, $B D N F, H T R 2 A, R O R A$, ST8SIA 2 and COMT) were previously analyzed in our Caucasian sample [27]. Two genes analyzed in Caucasians (MAPK1 and $Z N F 804 A$ ) were excluded from the analysis as previously independently analyzed in these samples [30, 38]. Other 7 new genes were also analyzed: HOMER1, NCAPG2, ESYT2, WDR60, SIGMAR1, S1OOB and TXNRD2.

\section{Statistical Analysis}

The HWE of alleles and the linkage disequilibrium (LD) among SNPs were analyzed using the Haploview software (v.3.2) for Windows [39]. Main statistical analyses were performed using the IBM SPSS package for windows (http://www. ibm.com/analytics/us/en/technology/spss/).

Single SNPs associations were tested by the Chi square test, logistic regression models when controlling for potential confounding factors, one-way analysis of variance/covariance or corresponding non-parametric tests. The statistical package "haplo.score" (R-project, http://cran.rproject.org/) was employed to compute block of alleles in LD (haplotypes) and test their association with the outcome variables.

The primary outcomes were represented by treatment effects in terms of response to 
Table 2 SNPs investigated

\begin{tabular}{|c|c|c|c|}
\hline Chr & Gene & $\begin{array}{l}\text { No. of SNPs; } \\
\text { valid (total) }\end{array}$ & SNPs \\
\hline 1 & PLA2G4A & $5(6)$ & rs10489407, rs6695515, rs10798069, $r s 10737276$, rs12144159, rs7414079 \\
\hline 2 & CREB1 & $2(4)$ & rs889895, rs6740584, rs2551922, rs2254137 \\
\hline 3 & CHL1 & $8(10)$ & $\begin{array}{l}\text { rs1516338, rs1516340, rs4003413, rs17271940, rs } 17274531, \text { rs } 9990005, \\
\text { rs331893, rs2272522, rs13078884, rs9841789 }\end{array}$ \\
\hline 3 & GSK3B & $4(5)$ & rs2037547, rs2873950, rs1719895, rs6782799, $r s 1381841$ \\
\hline 5 & HOMER1 & $8(8)$ & $\begin{array}{l}\text { rs3822568, rs6872497, rs4455546, rs12657371, rs12514775, rs6893883, } \\
\text { rs4132033, rs10042665 }\end{array}$ \\
\hline 7 & SP4 & $5(5)$ & rs2282888, rs2237304, rs10272006, rs12673091, rs9648275 \\
\hline 7 & NCAPG2 & $4(4)$ & rs10772, rs877279, rs12113120, rs4621754 \\
\hline 7 & $\begin{array}{l}\text { NCAPG2- } \\
\text { ESYT2 }^{\mathrm{a}}\end{array}$ & $2(3)$ & $r s 12668837$, rs9801117, rs6459896 \\
\hline 7 & ESYT2 & $6(6)$ & rs2013, rs3763406, rs3816462, rs2788469, rs842446, rs13233513 \\
\hline 7 & $\begin{array}{l}\text { ESYT2- } \\
\text { WDR60 }\end{array}$ & $2(2)$ & rs1039621, rs2657375 \\
\hline 7 & WDR60 & $6(6)$ & rs2657323, rs1188974, rs2788478, rs10275341, rs2527204, rs2657340 \\
\hline 7 & VIPR2 & $2(2)$ & rs3793222, rs2270313 \\
\hline 8 & PPP3CC & $4(4)$ & rs1522248, rs10108011, rs7430, rs2249098 \\
\hline 9 & SIGMAR1 & $1(2)$ & $r s 12115673, \mathbf{r s 1 0 8 1 4 1 3 0}$ \\
\hline 11 & $\mathrm{BDNF}$ & $7(7)$ & $\begin{array}{l}\text { rs1519480, rs7124442, rs6265, rs11030101, rs11030102, rs11030104, } \\
\text { rs12273363 }\end{array}$ \\
\hline 13 & HTR2A & $11(12)$ & $\begin{array}{l}\text { rs7323441, } r s 6314, \text { rs7997012, rs1923886, rs643627, rs2224721, rs582385, } \\
\text { rs17288723, rs2296973, rs6313, rs6311, rs1328685 }\end{array}$ \\
\hline 15 & RORA & $26(27)$ & $\begin{array}{l}\text { rs10438338, rs7167685, rs1657792, rs8040067, rs11630262, rs339996, } \\
\text { rs9806453, rs2553235, rs1020729, rs1871858, rs12900122, rs17204440, } \\
\text { rs12913922, rs341382, rs1673319, rs8041466, rs1234805, rs12148149, } \\
\text { rs11071570, rs4775340, rs2414687, rs7178442, rs } 1403737, \text { rs17270745, } \\
\text { rs809736, rs7177611, rs10519113 }\end{array}$ \\
\hline 15 & ST8SIA2 & $11(12)$ & $\begin{array}{l}\text { rs3759917, rs2305561, rs3784723, rs3784722, rs4777989, rs11629679, } \\
\text { rs7168443, rs2290492, rs8035760, rs11853992, rs } 17522085, \text { rs22279447 }\end{array}$ \\
\hline 21 & S100B & $7(8)$ & $\begin{array}{l}r s 9983498, \text { rs2839350, rs9722, rs2186358, rs2839364, rs2839365, } \\
\text { rs3788266, rs2839366 }\end{array}$ \\
\hline 22 & TXNRD2 & $2(2)$ & rs 4646310, rs2020917 \\
\hline
\end{tabular}


Table 2 continued

\begin{tabular}{llll}
\hline Chr & Gene & $\begin{array}{l}\text { No. of SNPs; } \\
\text { valid (total) }\end{array}$ & SNPs \\
\hline 22 & COMT & $6(6)$ & rs933271, rs5993883, rs740603, rs2239393, rs4680, rs174696 \\
\hline
\end{tabular}

All the SNPs genotyped in the Korean sample are reported in this table. Valid SNPs are shown in bold; those that were excluded from the analyses in italics (for details see "Methods" section)

a SNPs in these rows were located between two genes and, according to NCBI SNP database (https://www.ncbi.nlm.nih. gov/snp/), may affect both

antidepressant or mood stabilizers, remission and resistance to antidepressants. In secondary analyses, we tested genetic effects on disease risk (cases vs. controls) and disease-associated features (age of onset, history of suicide attempt, psychotic BD). The effect of potentially confounding factors was systematically checked, including age, sex and type of drug administered. Baseline symptoms severity (baseline HDRS and YMS scores) was used as a covariate when analyzing remission (not when analyzing response because it includes baseline severity by definition).

To limit the risk of false positives due to multiple testing, a Bonferroni correction was applied [40]. The corrected alpha-value was calculated dividing 0.05 for the number of genes analyzed $(0.05 / 19=0.0026)$. Power estimation was calculated through $G^{*}$ Power v.3.1.9.2 [41]. Considering a MAF of 0.30 , we had a sufficient power of 0.80 to detect odds ratios (OR) of 1.89 for the $\mathrm{BD}$ subsample and of 1.77 for the MDD subsample.

\section{Compliance with Ethics Guidelines}

All procedures followed were in accordance with the ethical standards of the responsible committee on human experimentation (institutional and national) and with the Helsinki Declaration of 1964, as revised in 2013. All the patients were informed in detail about the aims and the procedures of the study, and they signed an informed consent prior to inclusion into the study. The protocol and the informed consent were approved by the local ethical committee (approval number HC10TISI0031).

\section{RESULTS}

HWE test details are reported in supplementary Table 1.

\section{Genetic Effects on Treatment Efficacy}

Single SNPs were not significantly associated with response, remission with or resistance to antidepressant treatment in MDD, and neither were they significantly associated with response to or remission with mood stabilizers treatment in BD patients. However, some trends were observed. In MDD, $B D N F$ (rs1103010, $p=0.006$; rs11030104, $p=0.028 ;$ rs6265, $p=0.017$ ) and HOMER1 (rs10042665, $p=0.003 ;$ rs12514775. $p=0.011$ ) showed trends of association with response; RORA (rs1020729, $p=0.025$; rs11071570, $p=0.003 ;$ rs12148149, $p=0.045$; rs8041466, $p=0.040$ ) and HTR2A (rs643627, $p=0.008$ ) with remission; CHL1 (rs1516338, $p=0.008)$ with treatment resistance. Two $B D N F$ variants (s1519480, $p=0.003 ;$ rs7124442, $p=0.004$ ) also showed trends of association with response to mood stabilizers in $\mathrm{BD}$, in both single SNP and haplotype analysis. Further details are reported in supplementary Table 1.

\section{Secondary Outcomes}

Significant associations are reported in Table 3.

\section{Disease risk}

Two variants were found significantly associated with $\mathrm{BD}$ risk in case-control comparison: CHL1 rs4003413 and HTR2A rs643627 (Table 3). Four other SNPs in these genes (CHL1 


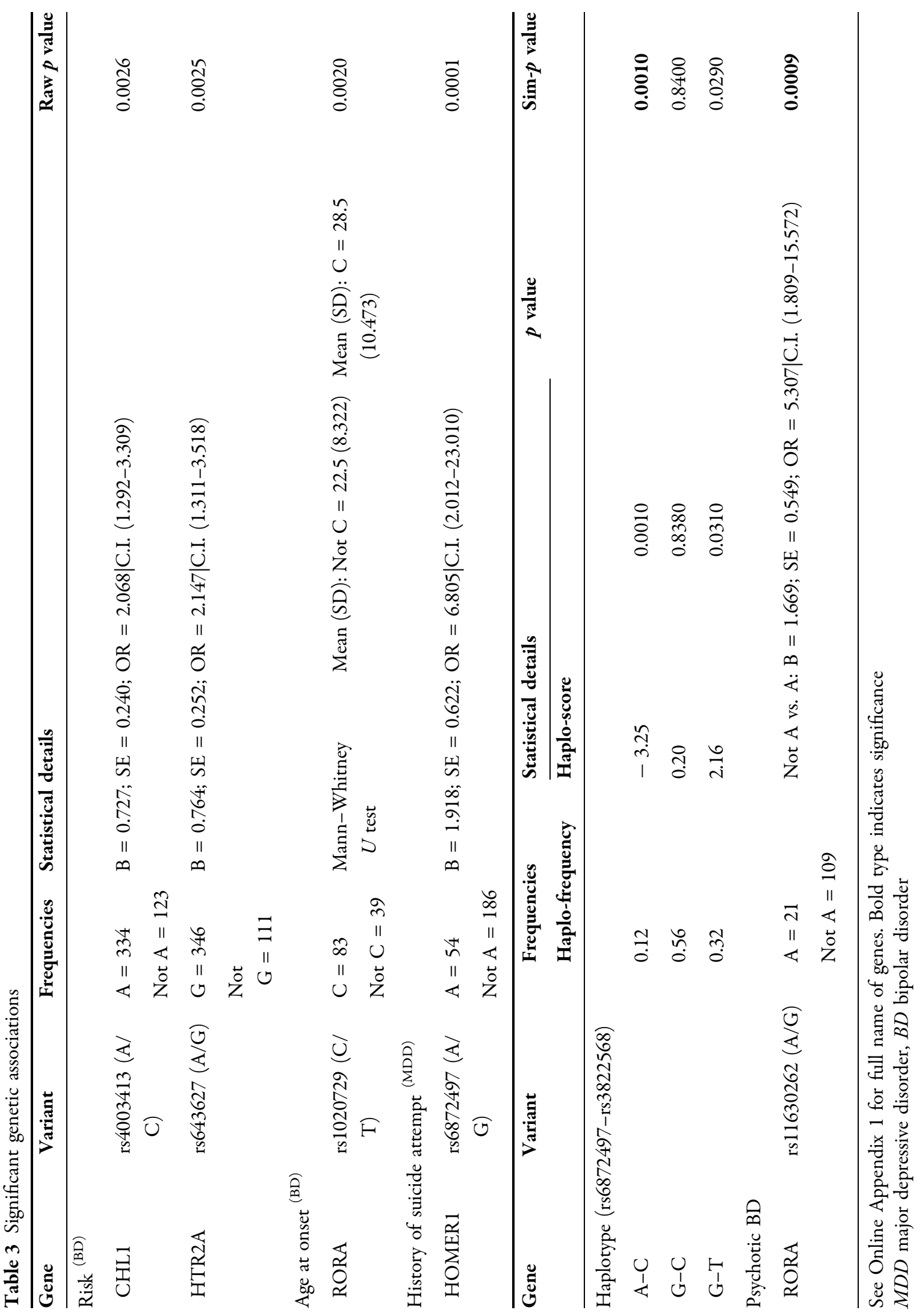


rs1516338, $p=0.029$ and $\operatorname{rs} 2272522, p=0.033$; HTR2A rs643627, $p=0.034$ and rs7997012, $p=0.028$ ) also showed trends of association with BD risk. A number of other genetic variants showed trends of association with BD risk, especially ST8SIA2 (rs11629679, rs3759917, rs3784723, rs4777989, rs8035760), RORA (rs10438338, rs12913922, rs17204440), BDNF (rs11030104, rs6265), GSK3B (rs1719895, rs2037547). Further details are reported in supplementary Table 2 . No genetic variant was associated with MDD risk in case-control analysis after Bonferroni correction. Only trends of association could be observed: RORA (rs10519113, rs12900122, rs8040067), CHL1 (rs1516340), COMT (rs2239393), HTR2A (rs2224721), SP4 (rs2237304) and ST8SIA2 (rs11629679, rs3784723).

Age at onset, suicide attempt, psychotic BD

Young age at onset in BD was significantly associated with RORA rs1020729 (Table 3). Interesting signals were also observed for age at onset, especially regarding COMT in $\mathrm{BD}$ (rs4680), but also $S 100 B$ in MDD (rs2839365, rs3788266, rs9722), and ST8SIA2 in both MDD (rs8035760) and BD (rs3759917). A variant in HOMER1, rs6872497, was significantly associated with history of previous suicide attempts in MDD subjects (Table 3). In particular, this SNP was also associated with a history of suicide attempts in haplotype combination with rs3822568 (Table 3). Other genes showed trends of association with suicide attempts in MDD subjects, especially variants located within and across ESYT2 and WDR60 (rs7997012, rs643627, rs1188974 and rs1188974-rs2788478 haplotype). Finally, a variant in RORA (rs11630262) also showed association with psychotic BD, along with two other nearly significant variations (rs11071570, rs2553235). Trends of association were also observed for BDNF and COMT. See supplementary Table 2 for further details.

\section{DISCUSSION}

The genes we investigated regulate the functioning of systems that have been previously reported as consistently involved in the mechanisms of action of antidepressant drugs and mood stabilizers [15-19]. Despite this, none of the genetic variants was found significantly associated neither with antidepressant treatment in MDD, nor with mood stabilizers in BD. However, some trends of effect were observed for SNPs within BDNF, HTR2A, RORA and CHL1. The only data in line with the previous work on the Caucasian population [27] concern the effect of CHL1 (rs1516338) on resistance to antidepressant drugs. CHL1 encodes for a neural recognition molecule, repeatedly implicated in antidepressant response [13, 42-47]. The possible association of BDNF, HTR2A (Serotonin receptor $2 \mathrm{~A}$ ) and, to a lower extent, RORA with the antidepressant response, not supported in our previous work, was however indicated by previous analyses on other samples [48, in which see refs: Bjorkholm, 2016 \#87; Hennings, 2015 \#73; Colle, 2015 \#89; Lin, 2014 \#20; Garriock, 2010 \#91].

When investigating the association with disease risk, CHL1 (rs4003413) and HTR2A (rs643627) were found to ne significantly associated with $\mathrm{BD}$ in case-control analysis, and with MDD as trends (other SNPs involved; see supplementary Table 2 ). These findings are in line with some previous evidence of the involvement of CHL1 in BD [49] and HT2A in both BD [50, 51] and MDD [52-55].

Two SNPs in RORA (rs1020729 and rs11630262) were associated with age at onset in $\mathrm{BD}$ and psychotic $\mathrm{BD}$, respectively. Other SNPs in RORA showed trends of association with both MDD and BD risk, and antidepressant treatment outcome. RORA is critically involved in the regulation of circadian rhythms, which are known to be core features of Mood disorders and other psychiatric disorders [56-58]. They can also be involved in the occurrence of psychotic symptoms in BD [59]. RORA was not previously implicated in $\mathrm{BD}$ [60], but it can impact on depressive, manic and psychotic symptoms [61-63], efficacy of treatments for depression [64], and treatment with lithium for BD [65].

HOMER1 was associated with suicide risk in MDD (rs6872497) and, as a trend, with antidepressant response (supplementary Table 1). HOMER1, implicated in stress response 
pathways [66], was previously hypothesized as involved in suicidal features $[67,68]$. Further, in BD, HOMER 1 has been shown to influence brain grey and white matter structure and function, long-term effects of lithium on white matter structure, and antidepressant response to chronotherapeutics, thus suggesting that glutamatergic neuroplasticity and Homer1 function might play a role in mood psychopathology and response to treatment [69]. The region with interesting genes ESYT2 and WDR6O (Chr 7) also provided trends of association with suicidal behavior (supplementary Table 2). However, to our knowledge, there are no reports regarding an involvement of ESYT2 or WDR60 in suicidal behavior. ESYT2 and WDR60 have both been implicated in neurodevelopmental pathways [70].

Finally, interesting genes that may potentially influence multiple disease features were ST8SIA2 and COMT. Regarding COMT, there is a rich literature about this gene and its implication in Mood disorders, being implicated in the metabolism of neurotransmitters [71-73]. Less evidence has been reported for ST8SIA2; its product modulates the adhesive properties of neural cell adhesion molecules, which mediate adhesion among neurons and between neurons and muscle. ST8SIA2 seems to be involved in multiple psychiatric disorders [74, 75].

\section{Strengths and Limitation}

Strengths are represented by: focus on genes that previously received substantial evidence of involvement in mood disorders (COMT, HTR2A, $B D N F, C H L 1$, Homer1 in particular); analysis of multiple SNPs within each gene; reanalysis in Asians of a set of genes previously tested for antidepressant response in Caucasians [27]; simultaneous evaluation of genetic effects on multiple disease phenotypes and critical associated features; and relatively large samples of affected subjects and healthy controls.

On the other hand, testing a large number of genetic variants on multiple phenotypes exponentially increases the risk of false positive results, especially on medium-sized samples. In some cases, the low allelic variability might decrease the power of the statistical analysis. However, we used a multiple testing correction that could be considered as overly conservative given the previous results. Further, we analyzed common SNPs only, but not other rare mutations or other polymorphic variants such as copy number variations or rare variants. Therefore, a complete coverage of the genes is not guaranteed. All recruited BD patients were in a manic or mixed phase. This made it possible to specifically evaluate the response to antimanic agents. On the other hand, it prevented the evaluation of antidepressant response in BD patients. Control subjects were recruited among hospital staff and patients. Although we checked for the absence of lifetime psychiatric conditions, as well as the absence of severe/ unstable medical or neurological conditions in control hospital patients, we cannot ensure full representativeness of our control sample with a control sample drawn from the normal population. Moreover, controls were not systematically evaluated for family history of psychiatric disease. Both patients and controls were consecutively collected and not matched for age and gender. However, cases and controls resulted to be similar in terms of age and gender. Patients underwent a naturalistic treatment and were not randomized to one or another treatment arm. All MDD patients were treated with paroxetine or venlafaxine for purposes prior to this work. Patients with BD were also treated with different mood stabilizers. There is the possibility of a potential confounding effects of different compounds; however, this has not been commonly observed in the previous studies (e.g., [76]). Furthermore, treatment outcomes were evaluated after the 6th and before the end of the 8th week of treatment in order to identify early predictors of response to treatments. However, this relatively short observation period may have led to an overestimation of the rates of non-response and treatment resistance. When focusing on component phenotypes (disease-associated features), we systematically collected only age at onset, suicidal behavior and psychotic BD. Psychosis in MDD was not systematically collected. The evaluation of other relevant phenotypic aspects could have highlighted a greater number of genetic effects. 
Finally, we could only detect small genetic effects with moderately sufficient size (OR > 2.00 ) only within secondary analyses in the BD sample (risk of illness, age of onset and psychotic BD) and history of attempted suicide in the MDD sample.

\section{CONCLUSIONS}

The present study was not able to identify major genetic effects on the response to pharmacological treatments for depression and manic/ mixed episodes in two samples of Asian ethnicity. Marginal results confirmed previous evidence on antidepressant response for CHL1, $B D N F, H T R 2 A$ and RORA, but none of sufficient magnitude to survive the statistical correction of significance. The analyses on secondary outcomes indicated a possible genetic modulatory effect on the risk of BD (CHL1, HTR2A) and a possible role of RORA in forms of BD characterized by early onset and psychotic symptoms. In MDD, HOMER1 could influence suicidal features. Given the several limitations of the present study, the results obtained should be interpreted in the light of the broader scientific literature.

\section{ACKNOWLEDGEMENTS}

Funding. This study was supported by a grant from the Korean Health Technology R\&D Project, Ministry of Health \& Welfare, Republic of Korea (grant number: HC15C1405), no funding or sponsorship was received for this study or publication of this article.

Authorship. All named authors meet the International Committee of Medical Journal Editors (ICMJE) criteria for authorship for this manuscript, take responsibility for the integrity of the work as a whole, and have given final approval for the version to be published.

Disclosures. Marco Calabrò, Laura Mandelli, Concetta Crisafulli, Soo-Jung Lee, Tae-Youn Jun, Sheng-Min Wang, Ashwin A. Patkar,
Prakash S. Masand, Francesco Benedetti, Changsu Han, Chi-Un Pae, and Alessandro Serretti have nothing to disclose.

Compliance with Ethics Guidelines. All procedures followed were in accordance with the ethical standards of the responsible committee on human experimentation (institutional and national) and with the Helsinki Declaration of 1964, as revised in 2013. All the patients were informed in detail about the aims and the procedures of the study and they signed an informed consent prior inclusion into the study. The protocol and the informed consent were approved by the local ethical committee (approval number HC10TISI0031).

Data Availability. The datasets during and/ or analyzed during the current study are available from the corresponding author on reasonable request.

Open Access. This article is distributed under the terms of the Creative Commons Attribution-NonCommercial 4.0 International License (http://creativecommons.org/licenses/ by-nc/4.0/), which permits any noncommercial use, distribution, and reproduction in any medium, provided you give appropriate credit to the original author(s) and the source, provide a link to the Creative Commons license, and indicate if changes were made.

\section{REFERENCES}

1. Kessler RC, Aguilar-Gaxiola S, Alonso J, Chatterji S, Lee S, Ormel J, Ustun TB, Wang PS. The global burden of mental disorders: an update from the WHO World Mental Health (WMH) surveys. Epidemiol Psichiatr Soc. 2009;18:23-33.

2. Rush AJ, Trivedi MH, Wisniewski SR, Nierenberg AA, Stewart JW, Warden D, Niederehe G, Thase ME, Lavori PW, Lebowitz BD, McGrath PJ, Rosenbaum JF, Sackeim HA, Kupfer DJ, Luther J, Fava M. Acute and longer-term outcomes in depressed outpatients requiring one or several treatment steps: a STAR*D report. Am J Psychiatry. 2006;163:1905-17.

3. Perlis RH, Ostacher MJ, Patel JK, Marangell LB, Zhang H, Wisniewski SR, Ketter TA, Miklowitz DJ, 
Otto MW, Gyulai L, Reilly-Harrington NA, Nierenberg AA, Sachs GS, Thase ME. Predictors of recurrence in bipolar disorder: primary outcomes from the Systematic Treatment Enhancement Program for Bipolar Disorder (STEP-BD). Am J Psychiatry. 2006;163:217-24.

4. Dedic N, Pohlmann ML, Richter JS, Mehta D, Czamara D, Metzger MW, Dine J, Bedenk BT, Hartmann J, Wagner KV, Jurik A, Almli LM, Lori A, Moosmang S, Hofmann F, Wotjak CT, Rammes G, Eder M, Chen A, Ressler KJ, Wurst W, Schmidt MV, Binder EB, Deussing JM. Cross-disorder risk gene CACNA1C differentially modulates susceptibility to psychiatric disorders during development and adulthood. Mol Psychiatry 2018; 23(3):533-543.

5. Rao S, Yao Y, Zheng C, Ryan J, Mao C, Zhang F, Meyre D, Xu Q. Common variants in CACNA1C and MDD susceptibility: a comprehensive metaanalysis. Am J Med Genet B 2016;171:896-903.

6. He K, An Z, Wang Q, Li T, Li Z, Chen J, Li W, Wang T, Ji J, Feng G, Lin H, Yi Q, Shi Y. CACNA1C, schizophrenia and major depressive disorder in the Han Chinese population. $\mathrm{Br} \mathrm{J}$ Psychiatry. 2014;204:36-9.

7. Krishnan V, Nestler EJ. Linking molecules to mood: new insight into the biology of depression. Am. J. Psychiatry. 2010;167:1305-20.

8. Vogelzangs N, Duivis HE, Beekman AT, Kluft C, Neuteboom J, Hoogendijk W, Smit JH, de Jonge P, Penninx BW. Association of depressive disorders, depression characteristics and antidepressant medication with inflammation. Transl Psychiatry. 2012;2:e79.

9. Zunszain PA, Hepgul N, Pariante CM. Inflammation and depression. Curr Top Behav Neurosci. 2013;14:135-51.

10. Cross-Disorder Group of the Psychiatric Genomics. C: identification of risk loci with shared effects on five major psychiatric disorders: a genome-wide analysis. Lancet. 2013;381:1371-9.

11. Gershon ES, Pearlson G, Keshavan MS, Tamminga C, Clementz B, Buckley PF, Alliey-Rodriguez N, Liu C, Sweeney JA, Keedy S, Meda SA, Tandon N, Shafee R, Bishop JR, Ivleva EI. Genetic analysis of deep phenotyping projects in common disorders. Schizophr Res. 2018;195:51-7.

12. Calati R, Crisafulli C, Balestri M, Serretti A, Spina E, Calabro M, Sidoti A, Albani D, Massat I, Hofer P, Amital D, Juven-Wetzler A, Kasper S, Zohar J, Souery D, Montgomery S, Mendlewicz J. Evaluation of the role of MAPK1 and CREB1 polymorphisms on treatment resistance, response and remission in mood disorder patients. Prog Neuropsychopharmacol Biol Psychiatry. 2013;44:271-8.

13. Fabbri C, Crisafulli C, Gurwitz D, Stingl J, Calati R, Albani D, Forloni G, Calabro M, Martines R, Kasper S, Zohar J, Juven-Wetzler A, Souery D, Montgomery S, Mendlewicz J, Girolamo GD, Serretti A. Neuronal cell adhesion genes and antidepressant response in three independent samples. Pharmacogenomics J. 2015;15:538-48.

14. Kato T. Molecular genetics of bipolar disorder. Neurosci Res. 2001;40:105-13.

15. Marsden WN. Synaptic plasticity in depression: molecular, cellular and functional correlates. Prog Neuropsychopharmacol Biol Psychiatry. 2013;43:168-84.

16. Mallei A, Failler M, Corna S, Racagni G, Mathe AA, Popoli M. Synaptoproteomic analysis of a rat geneenvironment model of depression reveals involvement of energy metabolism and cellular remodeling pathways. Int $\mathrm{J}$ Neuropsychopharmacol 2015;18(3):pyu067.

17. Fabbri C, Marsano A, Albani D, Chierchia A, Calati R, Drago A, Crisafulli C, Calabro M, Kasper S, Lanzenberger R, Zohar J, Juven-Wetzler A, Souery D, Montgomery S, Mendlewicz J, Serretti A. PPP3CC gene: a putative modulator of antidepressant response through the B-cell receptor signaling pathway. Pharmacogenomics J. 2014;14:463-72.

18. Niciu MJ, Ionescu DF, Mathews DC, Richards EM, Zarate CA Jr. Second messenger/signal transduction pathways in major mood disorders: moving from membrane to mechanism of action, part II: bipolar disorder. CNS Spectr. 2013;18:242-51.

19. D'Addario C, Palazzo MC, Benatti B, Grancini B, Pucci M, Di Francesco A, Camuri G, Galimberti D, Fenoglio C, Scarpini E, Altamura AC, Maccarrone M, Dell'Osso B. Regulation of gene transcription in bipolar disorders: role of DNA methylation in the relationship between prodynorphin and brain derived neurotrophic factor. Prog Neuropsychopharmacol Biol Psychiatry. 2018;82:314-21.

20. Lu B, Nagappan G, Lu Y. BDNF and synaptic plasticity, cognitive function, and dysfunction. Handb Exp Pharmacol. 2014;220:223-50.

21. Dityatev A, Bukalo O, Schachner M. Modulation of synaptic transmission and plasticity by cell adhesion and repulsion molecules. Neuron Glia Biol. 2008;4:197-209.

22. Nacher J, Guirado R, Varea E, Alonso-Llosa G, Rockle I, Hildebrandt H. Divergent impact of the polysialyltransferases ST8SiaII and ST8SiaIV on polysialic acid expression in immature neurons and 
interneurons of the adult cerebral cortex. Neuroscience. 2010;167:825-37.

23. Serretti A, Drago A, De Ronchi D. HTR2A gene variants and psychiatric disorders: a review of current literature and selection of SNPs for future studies. Curr Med Chem. 2007;14:2053-69.

24. Antypa N, Drago A, Serretti A. The role of COMT gene variants in depression: bridging neuropsychological, behavioral and clinical phenotypes. Neurosci Biobehav Rev. 2013;37:1597-610.

25. de Bartolomeis A, Latte G, Tomasetti C, Iasevoli F. Glutamatergic postsynaptic density protein dysfunctions in synaptic plasticity and dendritic spines morphology: relevance to schizophrenia and other behavioral disorders pathophysiology, and implications for novel therapeutic approaches. Mol Neurobiol. 2014;49:484-511.

26. Partonen T. Clock gene variants in mood and anxiety disorders. J Neural Transm (Vienna). 2012;119:1133-45.

27. Fabbri C, Crisafulli C, Calati R, Albani D, Forloni G, Calabro M, Martines R, Kasper S, Zohar J, JuvenWetzler A, Souery D, Montgomery S, Mendlewicz J, Serretti A. Neuroplasticity and second messenger pathways in antidepressant efficacy: pharmacogenetic results from a prospective trial investigating treatment resistance. Eur Arch Psychiatry Clin Neurosci. 2017;267:723-35.

28. Sheehan DV, Lecrubier $Y$, Sheehan KH, Amorim P, Janavs J, Weiller E, Hergueta T, Baker R, Dunbar GC. The Mini-International Neuropsychiatric Interview (M.I.N.I.): the development and validation of a structured diagnostic psychiatric interview for DSM-IV and ICD-10. J Clin Psychiatry. 1998;59(Suppl 20):22-33 (quiz 34-57).

29. Mandelli L, Wang SM, Han C, Lee SJ, Patkar AA, Masand PS, Pae CU, Serretti A. The impact of a single nucleotide polymorphism in SIGMAR1 on depressive symptoms in major depressive disorder and bipolar disorder. Adv Ther. 2017;34:713-24.

30. Calabro M, Mandelli L, Crisafulli C, Sidoti A, Jun TY, Lee SJ, Han C, Patkar AA, Masand PS, Pae CU, Serretti A. Genes involved in neurodevelopment, neuroplasticity, and bipolar disorder: CACNA1C, CHRNA1, and MAPK1. Neuropsychobiology. 2016;74:159-68.

31. Chiesa A, Pae CU, Porcelli S, Han C, Lee SJ, Patkar AA, Park MH, Jun TY, Serretti A. DAOA variants on diagnosis and response to treatment in patients with major depressive disorder and bipolar disorder. J Int Med Res. 2012;40:258-65.
32. Crisafulli C, Shim DS, Andrisano C, Pae CU, Chiesa A, Han C, Patkar AA, Lee SJ, Serretti A, De Ronchi D. Case-control association study of 14 variants of CREB1, CREBBP and CREM on diagnosis and treatment outcome in major depressive disorder and bipolar disorder. Psychiatry Res. 2012;198:39-46.

33. Pae CU, Chiesa A, Porcelli S, Han C, Patkar AA, Lee SJ, Park MH, Serretti A, De Ronchi D. Influence of BDNF variants on diagnosis and response to treatment in patients with major depression, bipolar disorder and schizophrenia. Neuropsychobiology. 2012;65:1-11.

34. Woo YS, Bahk WM, Pae CU, Jeong JH, Koo BH, Jon DI, Lee JG, Kim MD. Observational study to evaluate the clinical benefit of lamotrigine add-on therapy in bipolar patients in a naturalistic treatment setting. Asia-Pacific Psychiatry. 2014;6:334-41.

35. Hamilton M. A rating scale for depression. J Neurol Neurosurg Psychiatry. 1960;23:56-62.

36. Young RC, Biggs JT, Ziegler VE, Meyer DA. A rating scale for mania: reliability, validity and sensitivity. Br J Psychiatry. 1978;133:429-35.

37. Schosser A, Serretti A, Souery D, Mendlewicz J, Zohar J, Montgomery S, Kasper S. European Group for the Study of Resistant Depression (GSRD)where have we gone so far: review of clinical and genetic findings. Eur Neuropsychopharmacol. 2012;22:453-68.

38. Calabrò M, Mandelli L, Crisafulli C, Colombo R, Janiri L, Serretti A: ZNF804A rs1344706 and rs75957593 cross-diagnostic influence on psychosis and treatment improvement in Mood Disorders. submitted. (unpublished)

39. Barrett JC, Fry B, Maller J, Daly MJ. Haploview: analysis and visualization of LD and haplotype maps. Bioinformatics. 2005;21:263-5.

40. Shaffer JP. Multiple hypothesis testing. Annu Rev Psychol. 1995;46:561-84.

41. Faul F, Erdfelder E, Lang AG, Buchner A. G*Power 3: a flexible statistical power analysis program for the social, behavioral, and biomedical sciences. Behav Res Methods. 2007;39:175-91.

42. Clark SL, Adkins DE, Aberg K, Hettema JM, McClay JL, Souza RP, van den Oord EJ. Pharmacogenomic study of side-effects for antidepressant treatment options in STAR*D. Psychol Med. 2012;42:1151-62.

43. Morag A, Pasmanik-Chor M, Oron-Karni V, Rehavi M, Stingl JC, Gurwitz D. Genome-wide expression profiling of human lymphoblastoid cell lines identifies CHL1 as a putative SSRI antidepressant 
response biomarker. Pharmacogenomics. 2011;12:171-84.

44. Oved K, Morag A, Pasmanik-Chor M, Oron-Karni V, Shomron N, Rehavi M, Stingl JC, Gurwitz D. Genome-wide miRNA expression profiling of human lymphoblastoid cell lines identifies tentative SSRI antidepressant response biomarkers. Pharmacogenomics. 2012;13:1129-39.

45. Oved K, Morag A, Pasmanik-Chor M, Rehavi M, Shomron N, Gurwitz D. Genome-wide expression profiling of human lymphoblastoid cell lines implicates integrin beta- 3 in the mode of action of antidepressants. Transl Psychiatry. 2013;3:e313.

46. Oved K, Farberov L, Gilam A, Israel I, Haguel D, Gurwitz D, Shomron N. MicroRNA-mediated regulation of ITGB3 and CHL1 is implicated in SSRI action. Front Mol Neurosci. 2017;10:355.

47. Probst-Schendzielorz K, Scholl C, Efimkina O, Ersfeld E, Viviani R, Serretti A, Fabbri C, Gurwitz D, Lucae S, Ising M, Paul AM, Lehmann ML, Steffens M, Crisafulli C, Calabro M, Holsboer F, Stingl J. CHL1, ITGB3 and SLC6A4 gene expression and antidepressant drug response: results from the Munich antidepressant response signature (MARS) study. Pharmacogenomics. 2015;16:689-701.

48. Qesseveur G, Petit AC, Nguyen HT, Dahan L, Colle R, Rotenberg S, Seif I, Robert P, David D, Guilloux JP, Gardier AM, Verstuyft C, Becquemont L, Corruble E, Guiard BP. Genetic dysfunction of serotonin 2A receptor hampers response to antidepressant drugs: a translational approach. Neuropharmacology. 2016;105:142-53.

49. Noor A, Lionel AC, Cohen-Woods S, Moghimi N, Rucker J, Fennell A, Thiruvahindrapuram B, Kaufman L, Degagne B, Wei J, Parikh SV, Muglia P, Forte J, Scherer SW, Kennedy JL, Xu W, McGuffin P, Farmer A, Strauss J, Vincent JB. Copy number variant study of bipolar disorder in Canadian and UK populations implicates synaptic genes. Am J Med Genet B. 2014;165B:303-13.

50. Abdolmaleky HM, Yaqubi S, Papageorgis P, Lambert AW, Ozturk S, Sivaraman V, Thiagalingam S. Epigenetic dysregulation of HTR2A in the brain of patients with schizophrenia and bipolar disorder. Schizophr Res. 2011;129:183-90.

51. Ghadirivasfi M, Nohesara S, Ahmadkhaniha HR, Eskandari MR, Mostafavi S, Thiagalingam S, Abdolmaleky HM. Hypomethylation of the serotonin receptor type-2A Gene (HTR2A) at T102C polymorphic site in DNA derived from the saliva of patients with schizophrenia and bipolar disorder. Am J Med Genet B. 2011;156B:536-45.
52. Malone KM, Ellis SP, Currier D, John Mann J. Platelet 5-HT2A receptor subresponsivity and lethality of attempted suicide in depressed in-patients. Int J Neuropsychopharmacol. 2007;10:335-43.

53. Smith RM, Papp AC, Webb A, Ruble CL, Munsie LM, Nisenbaum LK, Kleinman JE, Lipska BK, Sadee W. Multiple regulatory variants modulate expression of 5-hydroxytryptamine $2 \mathrm{~A}$ receptors in human cortex. Biol Psychiatry. 2013;73:546-54.

54. Lin JY, Jiang MY, Kan ZM, Chu Y. Influence of 5-HTR2A genetic polymorphisms on the efficacy of antidepressants in the treatment of major depressive disorder: a meta-analysis. J Affect Disord. 2014;168:430-8.

55. Zhao X, Sun L, Sun YH, Ren C, Chen J, Wu ZQ, Jiang YH, Lv XL. Association of HTR2A T102C and A-1438G polymorphisms with susceptibility to major depressive disorder: a meta-analysis. Neurol Sci. 2014;35:1857-66.

56. Buoli M, Serati M, Grassi S, Pergoli L, Cantone L, Altamura AC, Bollati V. The role of clock genes in the etiology of Major Depressive Disorder: Special Section on "Translational and Neuroscience Studies in Affective Disorders". Section Editor, Maria Nobile $\mathrm{MD}, \mathrm{PhD}$. This Section of JAD focuses on the relevance of translational and neuroscience studies in providing a better understanding of the neural basis of affective disorders. The main aim is to briefly summaries relevant research findings in clinical neuroscience with particular regards to specific innovative topics in mood and anxiety disorders. J Affect Disord. 2018;234:351-7.

57. Melo MC, Garcia RF, Linhares Neto VB, Sa MB, de Mesquita LM, de Araujo CF, de Bruin VM. Sleep and circadian alterations in people at risk for bipolar disorder: a systematic review. J Psychiatr Res. 2016;83:211-9.

58. Johansson AS, Owe-Larsson B, Hetta J, Lundkvist GB. Altered circadian clock gene expression in patients with schizophrenia. Schizophr Res. 2016;174:17-23.

59. Serretti A, Benedetti F, Mandelli L, Calati R, Caneva B, Lorenzi C, Fontana V, Colombo C, Smeraldi E. Association between GSK-3beta -50T/C polymorphism and personality and psychotic symptoms in mood disorders. Psychiatry Res. 2008;158:132-40.

60. McGrath CL, Glatt SJ, Sklar P, Le-Niculescu H, Kuczenski R, Doyle AE, Biederman J, Mick E, Faraone SV, Niculescu AB, Tsuang MT. Evidence for genetic association of RORB with bipolar disorder. BMC Psychiatry. 2009;9:70.

61. Porcelli S, Lee SJ, Han C, Patkar AA, Albani D, Jun TY, Pae CU, Serretti A. Hot genes in Schizophrenia: 
how clinical datasets could help to refine their role. J Mol Neurosci. 2018;64:273-86.

62. Lai YC, Kao CF, Lu ML, Chen HC, Chen PY, Chen $\mathrm{CH}$, Shen WW, Wu JY, Lu RB, Kuo PH. Investigation of associations between NR1D1, RORA and RORB genes and bipolar disorder. PLoS ONE. 2015;10:e0121245.

63. Yeim S, Boudebesse C, Etain B. Belliviera F [Circadian markers and genes in bipolar disorder]. Encephale. 2015;41:S38-44.

64. Hennings JM, Uhr M, Klengel T, Weber P, Putz B, Touma C, Czamara D, Ising M, Holsboer F, Lucae S. RNA expression profiling in depressed patients suggests retinoid-related orphan receptor alpha as a biomarker for antidepressant response. Transl Psychiatry. 2015;5:e538.

65. Geoffroy PA, Etain B, Lajnef M, Zerdazi EH, Brichant-Petitjean C, Heilbronner U, Hou L, Degenhardt F, Rietschel M, McMahon FJ, Schulze TG, Jamain S, Marie-Claire C, Bellivier F. Circadian genes and lithium response in bipolar disorders: associations with PPARGC1A (PGC-1alpha) and RORA. Genes Brain Behav. 2016;15:660-8.

66. Wagner KV, Hartmann J, Mangold K, Wang XD, Labermaier C, Liebl C, Wolf M, Gassen NC, Holsboer F, Rein T, Muller MB, Schmidt MV. Homer1 mediates acute stress-induced cognitive deficits in the dorsal hippocampus. J Neurosci. 2013;33:3857-64.

67. Rao S, Leung CS, Lam MH, Wing YK, Waye MM, Tsui SK. Resequencing three candidate genes discovers seven potentially deleterious variants susceptibility to major depressive disorder and suicide attempts in Chinese. Gene. 2017;603:34-41.

68. Rao S, Lam MH, Yeung VS, Wing YK, Waye MM. Association of HOMER1 rs2290639 with suicide attempts in Hong Kong Chinese and the potentially functional role of this polymorphism. Springerplus. 2016;5:767.

69. Benedetti F, Poletti S, Locatelli C, Mazza E, Lorenzi C, Vitali A, Riberto M, Brioschi S, Vai B, Bollettini I, Melloni E, Aggio V, Falini A, De Bartolomeis A, Colombo C. A Homer 1 gene variant influences brain structure and function, lithium effects on white matter, and antidepressant response in bipolar disorder: a multimodal genetic imaging study. Prog Neuropsychopharmacol Biol Psychiatry. 2018;81:88-95.

70. Perche O, Menuet A, Marcos M, Liu L, Paris A, Utami KH, Kervran D, Cacheux V, Laudier B, Briault S. Combined deletion of two Condensin II system genes (NCAPG2 and MCPH1) in a case of severe microcephaly and mental deficiency. Eur J Med Genet. 2013;56:635-41.

71. Calabro M, Porcelli S, Crisafulli C, Wang SM, Lee SJ, Han C, Patkar AA, Masand PS, Albani D, Raimondi I, Forloni G, Bin S, Mattiaccio A, Mantovani V, Jun TY, Pae CU, Serretti A. Genetic variants within key nodes of the cascade of antipsychotic mechanisms: effects on antipsychotic response and Schizophrenia psychopathology in a naturalistic treatment setting in two independent Korean and Italian samples. Adv Ther. 2017;34:1482-97.

72. Wang M, Ma Y, Yuan W, Su K, Li MD. Meta-analysis of the COMT Val158Met polymorphism in major depressive disorder: effect of ethnicity. J Neuroimmune Pharmacol. 2016;11:434-45.

73. Gatt JM, Burton KL, Williams LM, Schofield PR. Specific and common genes implicated across major mental disorders: a review of meta-analysis studies. J Psychiatr Res. 2015;60:1-13.

74. Yang SY, Huh IS, Baek JH, Cho EY, Choi MJ, Ryu S, Kim JS, Park T, Ha K, Hong KS. Association between ST8SIA2 and the risk of Schizophrenia and bipolar I disorder across diagnostic boundaries. PLoS ONE. 2015; 10:e0139413.

75. Mandelli L, Emiliani R, Porcelli S, Fabbri C, Albani D, Serretti A. Genes involved in neuroplasticity and stressful life events act on the short-term response to antidepressant treatment: a complex interplay between genetics and environment. Hum Psychopharmacol. 2014;29:388-91.

76. Chiesa A, Lia L, Alberti S, Lee SJ, Han C, Patkar AA, Pae CU, Serretti A. Lack of influence of rs4680 (COMT) and rs6276 (DRD2) on diagnosis and clinical outcomes in patients with major depression. Int J Psychiatry Clin Pract. 2014;18:97-102. 